\title{
Shelf life extension of sweetpotato (Ipomoea batatas (L) Lam) storage roots using household-level storage methods
}

\author{
Richard Atinpoore Atuna \\ Department of Biotechnology and Molecular Biology, \\ University for Development Studies, \\ P.O. Box 1882, Tamale, Ghana \\ Email: richtuna024@gmail.com

\section{Edward Ewing Carey} \\ International Potato Center, \\ c/o CSIR Savanna Agricultural Research Institute (SARI), \\ P.O. Box 3785, Kumasi, Ghana \\ Email: e.carey@cgiar.org
}

\section{Francis Kweku Amagloh*}

Department of Food Science and Technology, University for Development Studies, P.O. Box 1882, Tamale, Ghana Email: fkamagloh@uds.edu.gh ${ }^{*}$ Corresponding author

\begin{abstract}
Three sweetpotato cultivars; OFSP-1, OFSP-2 and WFSP were investigated for storability using two storage methods (heap vs. sand box), following curing (dehaulming, field-piled or no curing). Storage roots (SRs) were subsequently stored using either heap or sand box methods. SRs were deliberately injured and wound healing assessed over a 6-day period. Over an 11 week storage period, OFSP-2 recorded the highest weight loss $(9.7 \%$; $p=0.04)$, weevil damage $(3.7 \% ; p=0.49)$ and rot $(21 \% ; p<0.001)$. Weight loss and weevil damage were respectively 1.8-times and 23-times higher in the SRs stored in heap method compared with those in the sand box method. Except for WFSP, the wound healing score increased gradually to the 3rd or 4 th day for OFSP-2 and OFSP-1 respectively before levelling off. The sand box method performed better than heap storage should be encouraged for the storage of sweetpotato SRs at the household-level.
\end{abstract}

Keywords: dehaulming; lignification; sand box; wound healing; sweetpotato.

Reference to this paper should be made as follows: Atuna, R.A., Carey, E.E. and Amagloh, F.K. (2017) 'Shelf life extension of sweetpotato (Ipomoea batatas (L) Lam) storage roots using household-level storage methods', Int. J. Postharvest Technology and Innovation, Vol. 5, No. 4, pp.274-285. 


\begin{abstract}
Biographical notes: Richard Atinpoore Atuna is a Masters student in the Department of Biotechnology and Molecular Biology, University for Development Studies, Tamale Ghana. He received his BSc in Agricultural Technology (Biotechnology option) in 2012 at the University for Development Studies, Tamale Ghana. He is currently a research assistant on the RING project, which seeks to get $\beta$-carotene rich food crops to rural households in northern Ghana.
\end{abstract}

Edward Ewing Carey is based at the CSIR-Crops Research Institute, Kumasi, Ghana and works as a sweetpotato breeder and Ghana Country manager for the International Potato Center. His interest is in assisting to develop new sweetpotato cultivars that are fit for diversified end-uses. He works to achieve the objectives of the sweetpotato for profit and health initiative, which seeks to bring the benefits of sweetpotato to more than 10 million households by the year 2020 .

Francis Kweku Amagloh is a Senior Lecturer and Head of Department of the Food Science and Technology Department, at the University for Development Studies Tamale, Ghana. He obtained his Doctorate in Human Nutrition from Massey University, Palmerston North, New Zealand and Master in Food Technology from the Kwame Nkurumah University of Science and Technology Kumasi, Ghana. His current research interest lies in improving the vitamin A and iron status and general nutrition of women and children using recipes developed from vitamin A and iron rich food sources.

\title{
1 Introduction
}

Among the root and tuber crops, sweetpotato [Ipomoea batatas (L) Lam] is globally ranked as the third most important food crop based on production, and in Ghana fourth (Faostat3.fao.org, 2013). Sweetpotato performs well under suitable conditions but can still give good yields under marginal conditions (Nedunchezhiyan and Ray, 2010). Therefore, sweetpotato can be a food security crop in developing countries where agricultural inputs such as fertiliser and irrigation are limited.

Sweetpotato, particularly the orange- and purple-fleshed cultivars have been shown to significantly improve human nutrition and overall health (Bovell-Benjamin, 2007). Therefore, its availability for regular household consumption is important.

Although sweetpotato generally contains high moisture (60-70\%) (Tomlins et al., 2010); the orange-fleshed sweetpotato (OFSP) cultivars in particular are slightly higher (60-80\%) (Tumwegamire et al., 2014). The perishability of sweetpotato has been attributed to the low dry matter contents (Tomlins et al., 2010) coupled with the thin delicate skin (Woolfe, 1992). It stores barely only a few days to weeks, and variability on storage quality is cultivar and environment dependent especially temperature and relative humidity (Ray et al., 2010).

Commercially, post-harvest curing of sweetpotato roots at temperatures ranging from $29^{\circ} \mathrm{C}$ to $33^{\circ} \mathrm{C}$ and relative humidity from $90 \%$ to $95 \%$ improves the shelf life by up to one year (Woolfe, 1992). Curing encourages the formation of lignified/suberised wound periderm tissue at the wound sites (Tomlins et al., 2010) which reduce moisture loss and microbial infection, reducing root decay (Ravi et al., 1996; Ray and Ravi, 2005; Sowley and Oduro, 2002). However, other factors aside from wound 
healing through lignification are considered in selecting cultivars with good storage potentials (Amand and Randle, 1991; Walter et al., 1989). Although found to be beneficial, curing is hardly practised by farmers in the tropics but may occur naturally where ambient conditions are moist and warm (Ravi et al., 1996; Woolfe, 1992).

According to Jenkins (1982), sweetpotato is commonly stored in shallow earthen piles in low-income countries. Similarly, commercial sweetpotato farmers in tropical countries like Ghana mostly use the heap or pit storage methods (personal observation). These methods have been reported to be unsatisfactory (Hayma, 2003). For instance, average losses up to the ranges of $20-25 \%$ have been reported in shallow earthen pile storage (Jenkins, 1982). The main causes have been weight loss, insect damage and rot. The physiological weight loss of sweetpotato cultivars was higher (25\%) after 25 days of storage in exposed heap storage, but in sand medium or saw dust the losses were $15 \%$ and $17 \%$, respectively, even after 75 days of storage (Chattopadhyay et al., 2006).

In Ghana, most commercial sweetpotato farmers in Bawku Municipality $10^{\circ} 15^{\prime}$ 07.56" and $0^{\circ} 43.22^{\prime \prime} \mathrm{W}$ ), Upper East Region, use an incidental curing (field-piled), prior to heap and/or pit storage of their SRs. It is incidental because harvested SRs are heaped on the farm covered with fresh sweetpotato vines for several weeks until there is enough space at home for storage. The effectiveness of this possible curing option needs to be evaluated. Alternatively, dehaulming (removing the canopy) one week before harvest has been reported to improve the market quality of roots by $48 \%$ (Tomlins et al., 2007). However, there is little information on the influence of dehaulming on post-harvest shelf life extension of sweetpotato. Therefore, there is the need for further studies on the potential of dehaulming and extension of the shelf life of sweetpotato as cultivars may respond differently to this pre-harvest treatment.

Storage of agricultural produce is crucial in ensuring availability of food beyond the harvest period. A 'sand, storage and sprouting' (triple S) system has been developed to preserve roots in dry cool sand, which are planted prior to the onset of the rainy season and produce sprouts for vine multiplication prior to planting (Namanda et al., 2013). It should, therefore, be possible to use the same method for storage of sweetpotato for food. Therefore, in this study the triple S system, adopted as a sand box, is compared with farmers' root storage (heap method) as methods of extending the shelf life of roots to which pre- and post-harvest treatments (in-ground and field-piled curing) have been applied. The wound healing potential of the three cultivars following root injury was also considered.

\section{Materials and methods}

\subsection{Study location}

The fieldwork was carried out in the research field of the Council for Scientific and Industrial Research (CSIR)-Savanna Agricultural Institute (SARI), Nyankpala, Tamale, in the northern part of Ghana in August, 2014. The storage experiment was also carried out at the Faculty of Agriculture, University for Development Studies, Nyankpala campus, Northern Region. Both areas fall within the Savanna Agro-ecological Zone of Ghana. 


\subsection{Cultivar}

OFSP-1 is one of the two farmer cultivars under advanced trial for release by CSIRSARI, while OFSP-2 was released in Ghana in 2005 by CSIR-Crops Research Institute as Apomuden. WFSP is a popular commercial white-fleshed farmer cultivar cultivated in Bawku, Upper East region, Ghana.

Late maturing cultivars (OFSP-1 and WFSP) were planted a month earlier (August-December, 2014, four months) than the early maturing cultivar, OFSP-2 (September-December, 2014; three months).

\subsection{Experimental design}

A completely randomised design was used for the root production while a $3 \times 3 \times 2$ factorial design was used for the storage. Three curing options: dehaulming, field-piled and no curing; three cultivars of sweetpotato (OFSP-1, OFSP-2 and WFSP) and two storage methods (heap and sand box) in triplicates.

\subsection{Curing}

\subsubsection{In-ground (dehaulming)}

The canopy of the sweetpotato plants was removed at maturity with a sharp knife, leaving about $30 \mathrm{~cm}$ to the base and allowed to cure in-ground for seven days before harvest.

\subsubsection{Field-piled}

Sweetpotato SRs were harvested at maturity, sorted and heaped on straw and then covered with fresh sweetpotato vines and allowed to cure on the field.

\subsubsection{Wound healing and lignification test}

About seven SRs from each cultivar were taken for lignification and wound healing test. Each root was deliberately injured after harvest at three different points using a sweetpotato peeler prior to field-piled curing. The wounds were assessed daily based on Weiners' phloroglucinol-HCl test as described by van Oirschot et al. (2001) for a period of six days. The wounds were stained with phloroglucinol for the presence or absence of lignin. A lignification score; 0 for no lignification, 0.5 for patchy lignification and 1 for complete lignification was used. A lignification index (LI) was obtained from the average of three wounds.

\subsubsection{No curing}

Freshly harvested SRs were sorted and immediately stored as heap or sand box.

\subsection{Storage and storage type}

The pre- and post-harvest cured as well as uncured samples of the three cultivars were separately pooled and stored as a heap or in the sand box in three replications in a laterite house roofed with thatch. 


\subsubsection{Heap method}

About $5 \mathrm{~kg}$ of each cultivar from pre-harvest (dehaulming), post-harvest (field-piled curing) and non-cured samples were tied in a net bag. The tied heaps were then placed on the floor layered with rice straw. The heaps were then covered with rice straw and water was then sprinkled once every third day as practised by farmers.

\subsubsection{Sand box method}

Earthen sand boxes were constructed in the storage house with dimension $0.5 \times 0.5 \times$ $0.6 \mathrm{~m}$. Equal weights $(5 \mathrm{~kg}$ ) of sweetpotato SRs from each curing method were loosely tied in a net bag for easy retrieval from the sand for assessment. The bag with roots was placed on cool dry river sand, making sure the individual roots were separated to partition between roots with sand. Afterwards, the bag was layered with sand to completely cover the roots.

\subsubsection{Root quality}

Weight loss, weevil damage, rot and sprouts scores were considered as an index of root quality during storage.

\subsubsection{Percent weight loss}

Weight loss was carried out during field-piled curing and storage. It was expressed as a percentage of weight with respect to initial weight at day one and final weight a day seven as described by Amoah et al. (2011).

\subsubsection{Shrinkage}

Three sound SRs of each cultivar in the field-piled curing were used for measuring shrinkage. Using a Vernier caliper, the diameter of each root was measured and the points of contact with the caliper marked with a permanent marker for subsequent measurements. Shrinkage was expressed as a percentage of initial root diameter on day one relative to the final root diameter on the seventh day as described elsewhere (Amoah et al., 2011).

\subsubsection{Percent rot, sprouts and weevil damage}

Percent rots, sprouts and weevils were calculated using the ratio of the number of decayed roots, occurrence of sprouting and weevil infestation to the total number of roots, respectively.

\subsection{Statistical analysis}

Data were analysed using (GenStat Discovery, 2011). One-way analysis of variance using unbalanced treatment structure was employed for the analysis of storage data while one-way analysis of variance with balanced treatment structure was used for weight loss, 
shrinkage and lignification index during field-piled curing. The interaction between cultivar and curing time prior to storage as well as cultivar and curing method was considered for the lignification and storage, respectively. Predicted means from unbalanced treatment structure and means from the balanced treatment structures were separated using Fishers least significant difference.

\section{Results and discussion}

\subsection{Weight loss and shrinkage during curing prior to storage}

The results on weight loss and shrinkage which was the difference between the first and last day of field-piled curing expressed as a percentage are presented in Figure 1. During the 7-days field-piled curing, weight loss and shrinkage with regards to the cultivars were: $7.3 \%, p=0.31 ; 4.2 \%, p=0.32$, respectively. This supports earlier studies that weight loss in sweetpotato ranges from 1.0-7.0\% during curing (Ravi et al., 1996; Scott and Mathews, 1957). The loss in weight and shrinkage could be due to the high rates of metabolic activities such as respiration and transpiration during curing (Walter et al., 1989). Although not significant, OFSP-2 had the least weight loss and shrinkage followed by WFSP and lastly OFSP-1.

Figure 1 Percent weight loss and shrinkage of sweetpotato cultivars during a 7-day field-piled curing

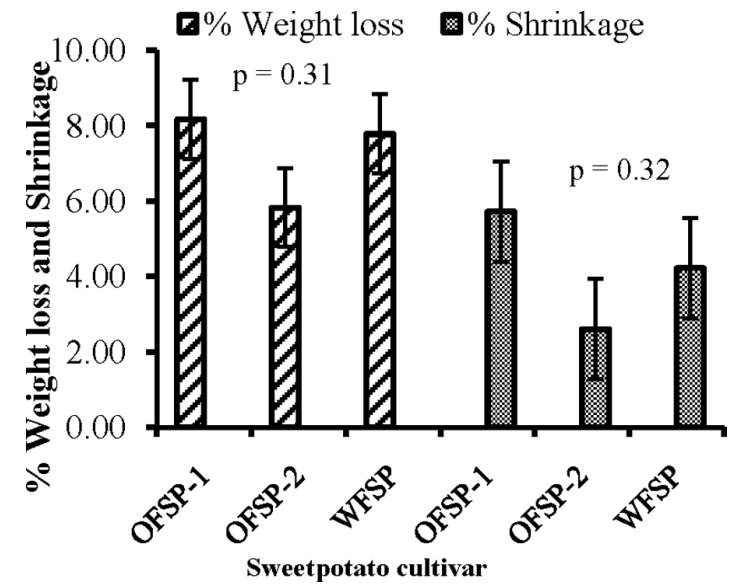

Bar values (least square means \pm standard error of the means, $n=3$ ).

\subsection{Effect of pre-harvest (dehaulming) and post-harvest (field-piled) curing on cultivars SR quality during 11 weeks storage}

Cultivars' response to pre- and post-harvest treatments was not distinctively different regarding root quality parameters: Weight loss $(p=0.50)$; weevil damage $(p=0.68)$; $\operatorname{rot}(p=0.46)$ and sprouts $(p=0.06)$ is shown in Figure 2 . 
Figure 2 Cultivars' response to pre and post-harvest treatment

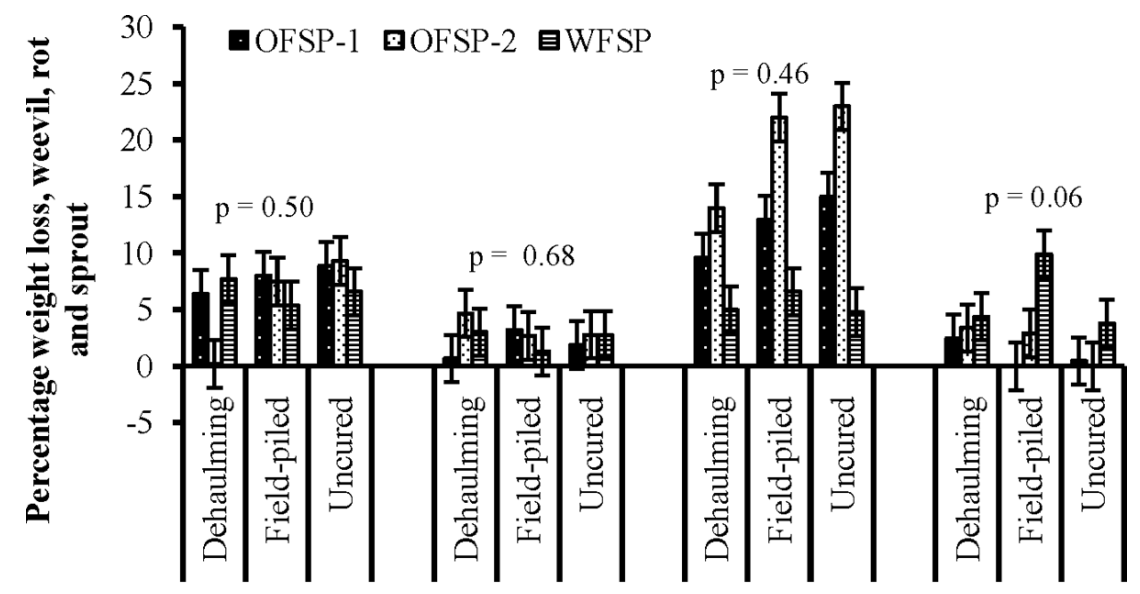

Pre- and post-harvest curing methods

Bar values (least square means \pm standard error of means, $n=3$ ).

In the root quality assessment, rots were the biggest concern for the OFSP cultivars. Generally, the WFSP produced more sprouts than OFSP cultivars. This could be due to differences in dormancy periods with WFSP having a relatively shorter dormancy period than to OFSP cultivars. The curing treatments gave more sprouts than the no-curing after harvest. This data suggest that for vine multiplication using the triple $\mathrm{S}$ system, curing should be a treatment to consider.

Pre- and post-harvest treatments did not positively influence cultivars in terms of weevil damage and sprouts as the control (uncured) recorded less in certain instances than the pre- and post-harvest treatment.

\subsection{Lignification and wound healing in field-piled curing}

Lignin deposition after wounding, scored as lignification index, was significantly different $(p<0.001)$ among the sweetpotato cultivars (Figure 3). OFSP-2 and WFSP showed good keeping potentials based on their high lignification scores of 0.81 and 0.79 , respectively. A high lignification score indicates good wound healing ability, thus reducing water loss and rotting and leading to improved storability of roots (van Oirschot et al., 2001). However, in our present study, OFSP-2, though had the highest lignification score, did not store better than OFSP-1 and WFSP (Figure 4). Our findings support previous suggestions that other factors aside from lignification (Amand and Randle, 1991; Walter et al., 1989) could be responsible for sweetpotato shelf life extension of the cultivars investigated in this study.

Formation of lignin after wounding increased with curing time (Figure 5) as was found in previous work by other researchers (Walter et al., 1989). The data suggest that the rapid lignification of WFSP could have been responsible for the lower scores of rots (Figure 4) compared with the other cultivars. Except for WFSP, the lignification score increased gradually to the 3rd or 4th day for OFSP-2 and OFSP-1, respectively, before levelling off. 
Figure 3 Lignification index of sweetpotato cultivars in field-piled curing

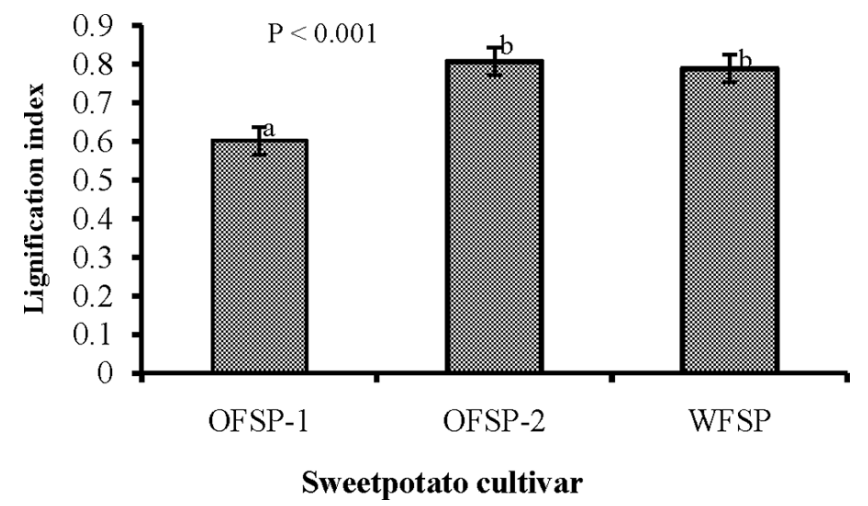

Bar values (least square means \pm standard error of the means, $n=3$ ).

Means with the same letter are not significantly different $(p>0.05)$.

Figure 4 Lignification index during field-piled curing

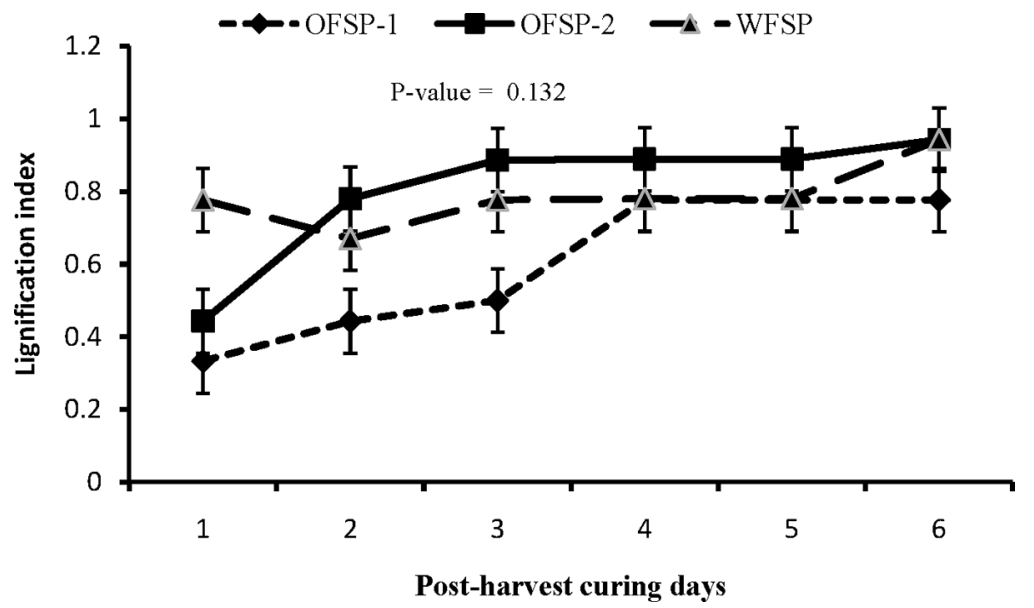

Bar values are (least square means \pm standard error of the means, $n=3$ ).

\subsection{Percent weight loss, rots, weevils and sprout during storage}

Among the cultivars stored, weight loss of WFSP was significantly lower by $7.05 \%$, $(p=0.04)$ than OFSP-2 but not OFSP-1 (Figure 4). Previously, Picha (1986) reported that 2 WFSP cultivars ('White star', 'Rojo Blanco') and Jewel (OFSP) were suitable for longterm storage because of their low rate of weight loss and absence of internal pithiness.

The above finding implies that OFSP-1 stores well and looks promising for household-level storage for food. OFSP-2 recorded highest rots $(21 \% ; p=0.001)$ about 1.6 and 3.6 times higher than OFSP-1 and WFSP respectively (Figure 5). The possible reason for this observation could be that OFSP-2 is very susceptible to rots due to its thin skin that can easily be damaged serving as entry points for pathogenic microorganisms leading to rot. Although it was beyond the objectives of this present study, identification of the type of rot during the root quality assessment could have provided vital data. This, however, should be considered in future studies. 
Figure 5 Sweetpotato quality parameters after 11 weeks of storage

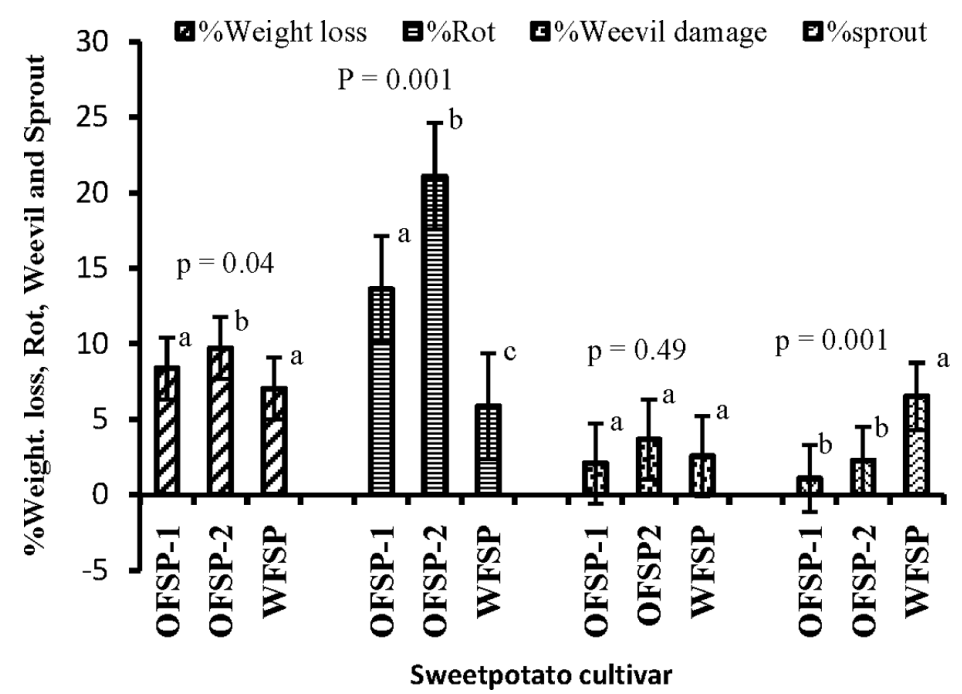

Bar values are (least square means indices \pm standard error of the means, $n=3$ ).

Least square means with the same alphabets are not significantly different $(p>0.05)$.

Among the three cultivars, weevil damage was found not to be significantly different $(p=0.49)$ during storage irrespective of the curing treatment option employed.

The WFSP and OFSP-1 had good keeping qualities among the cultivars stored. This implies that OFSP-1, which is under advanced trials for release in Ghana, has good storage potentials (up to two months) and could serve as a household-level dietary source of vitamin A.

\subsection{Storage type}

Figure 6 shows the results of the two storage methods and how they affected damage factors during the 11 weeks of storage. Significant differences were observed between the two storage methods in all the damage factors: Weight loss $(p=0.001)$; sprout $(p=0.001)$ and weevil damage $(p=0.001)$ except for percentage rot $(p=0.07)$.

Weight loss, rots and weevil damage in the heap storage were about 1.8, 1.1 and 23.0 times, respectively, higher than sand box storage. The current findings support earlier suggestion that physiological weight loss of sweetpotato cultivars was higher $(25 \%)$ after 25 days of storage in exposed heap storage, but in the sand medium or saw dust the losses were $15 \%$ and $17 \%$, respectively, even after 75 days of storage (Chattopadhyay et al., 2006). Reduced evapotranspiration rates leading to low moisture loss may have contributed to the lower weight loss in the sand box compared with the heap method.

Sweetpotato in the sand box method sprouted about three times higher than the heap method contrary to the findings of Chattopadhyay et al. (2006) that storage in sand medium was devoid of sprouts. The observed sprouts in the sand box could be an indication of good quality roots as van Oirschot et al. (2007) speculated that sound or healthy roots sprout readily. 
Figure 6 Sweetpotato attributes as affected by storage type over 11 weeks

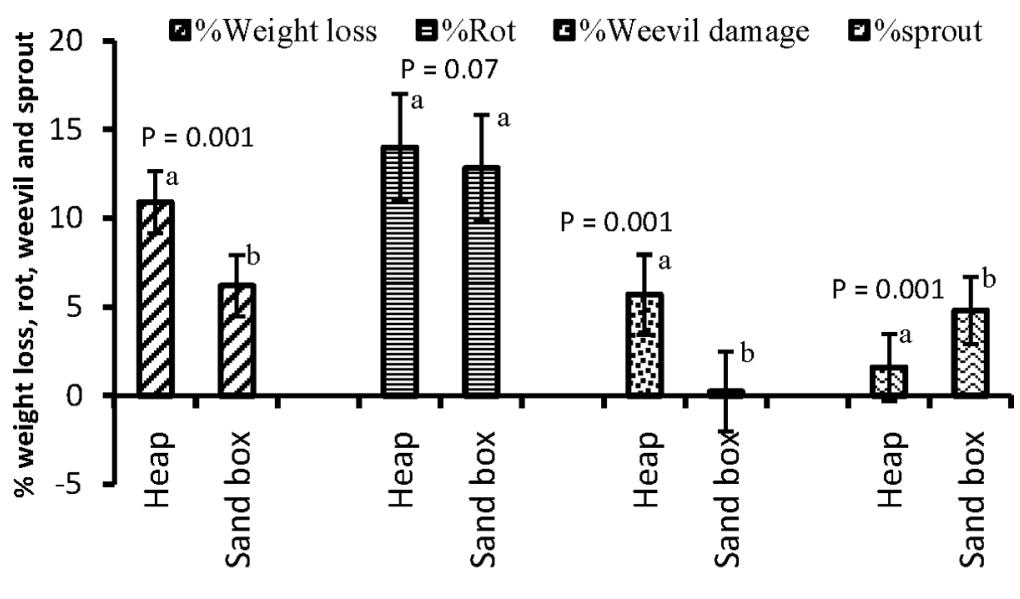

Storage type

Bar values (least square means \pm standard error of the means, $n=3$ )

Least means with the same alphabets are not significantly different $(p>0.05)$.

According to Edmunds et al. (2008), by the USDA standards, sprouts over three-fourths inch (approximately $2 \mathrm{~cm}$ ) longer are considered a defect. However, the lengths of the sprouts were not considered and have been acknowledged as a limitation of this study and should be considered in the subsequent studies.

The data on the low incidence of weevil damage of the roots stored in the sand box method indicate that the sand medium served as a block restricting the movement of the weevils from one root to the other. The findings of this study, therefore, suggests that sweetpotato (OFSP) can be stored in sand boxes up to 11 or more weeks for household consumption for food and nutrition security in northern Ghana.

The sand box described above when adopted can improve the shelf life of sweetpotato especially OFSP for at least two months after harvest instead of the few weeks. This could ensure regular consumption by rural poor farmers in northern Ghana. The dietary vitamin A status of children could be improved as found in another study by van Jaarsveld et al. (2005). Although potential use of the sand box storage for householdlevel storage of sweetpotato looks promising, there is the need for further research into the potentials of this storage for commercial purpose.

\section{Conclusions}

Sweetpotato cultivars showed similar response regarding root quality parameters with pre-harvest (dehaulming) and post-harvest (field-piled curing) treatments. Cultivars differed widely in their wound healing ability. The relationship between cultivars' wound healing ability and root quality parameters was erratic as OFSP-2 with the highest lignification score stored poorly while OFSP-1 stored better though had the least lignification score. WFSP and OFSP-1 had good storage potentials regarding root quality parameters considered. However, weevil damage, though not significant, OFSP-2 was prone to weevil damage compared to WFSP and OFSP-1. 
The sand box storage, improved the shelf life of sweetpotato cultivars up to 11 weeks. Therefore, the sand box can be used for homestead storage of sweetpotato especially OFSP cultivars for household consumption for improved vitamin A and overall nutrition in northern Ghana.

\section{Acknowledgement}

We acknowledge support from the USAID-OFDA grant by the International Potato Center. We also appreciate and value the theses grant received from Association of African Universities.

\section{References}

Amand, P.C.S. and Randle, W.M. (1991) 'Ethylene production as a possible indicator of wound healing in roots of several sweet potato cultivars', Euphytica, Vol. 53, pp.97-102.

Amoah, R.S., Teye, E., Abano, E.E. and Tetteh, J.P. (2011) 'The storage performance of sweet potato with different pre-storage treatments in an evaporative cooling barn', Asian Journal of Agricultural Research, Vol. 5, No. 2, pp.137-145.

Bovell-Benjamin, A.C. (2007) 'Sweetpotato: review of its past, present, and future role in human nutrition', Advances in Food and Nutrition Research, Vol. 52, pp.1-59.

Chattopadhyay, A., Chakraborty, I., Kumar, P.R., Nanda, M.K. and Sen, H. (2006) 'Uncontrolled storage behaviour of sweet potato (Ipomoea batatas L. Lam)', Journal of Food Science and Technology-Mysore, Vol. 43, No. 1, pp.41-45.

Edmunds, B.A., Boyette, M.D., Clark, C.A., Ferrin, D.M., Smith, T.P. and Holmes, G.J. (2008) Post-Harvest Handling of Sweetpotatoes, North Carolina State University Cooperative Extension Service.

Faostat3.fao.org (2013) Food and Agriculture Organisation of the United Nations Statistics Division, Retrieved 20 October, 2015, from http://faostat3. fao. org/download/Q/QC/E

GenStat Discovery (2011) GenStat for Windows, Release 10.3 DE Discovery Ed. 4, VSN International Ltd., Rothamsted Experimental Station.

Hayma, J. (2003) The Storage of Tropical Agricultural Products, 4th ed., Agromisa Foundation, Wageningen, Wageningen, The Netherlands.

Jenkins, P.D. (1982) 'Losses in sweet potatoes (Ipomoea batatas) 'stored under traditional conditions in Bangladesh', Journal of Tropical Science, Vol. 24, No. 1, pp.17-28.

Namanda, S., Amour, R. and Gibson, R. (2013) 'The triple S method of producing sweet potato planting material for areas in Africa with long dry seasons', Journal of Crop Improvement, Vol. 27, No. 1, pp.67-84.

Nedunchezhiyan, M. and Ray, R.C. (2010) 'Sweet potato growth, development, production and utilization: overview', in Ray, R.C. and Tomlins, K.I. (Eds.): Sweet Potato: Post Harvest Aspects in Food, Nova Science Publishers, Inc., New York City, pp.2-26.

Picha, H.D. (1986) 'Weight loss in sweetpotatoes during curing and storage: contribution of transpiration and respiration', American Society for Horticultural Science, Vol. 111, No. 6, pp.889-892.

Ravi, V., Aked, J. and Balagopalan, C. (1996) 'Review on tropical root and tuber crops I. Storage methods and quality changes', Critical Reviews in Food Science and Nutrition, Vol. 36, No. 7, pp.661-709.

Ray, R.C. and Ravi, V. (2005) 'Post-harvest spoilage of sweetpotato in tropics and control measures', Critical Reviews in Food Science and Nutrition, Vol. 45, No. 7-8, pp.623-644. 
Ray, R.C., Ravi, V., Hegde, V., Rao, K.R. and Tomlins, K.I. (2010) 'Post harvest handling, storage methods, pest and diseases of sweet potato', in Ray, R.C. and Tomlins, K.I. (Eds.): Sweet Potato: Post Harvest Aspects in Food, Nova Science Publishers, Inc., New York, pp.27-57.

Scott, L.B. and Mathews, W.A. (1957) 'Carbohydrate changes in sweet potatoes during curing and storage', Proceedings. American Society for Horticultural Science, Vol. 70, 407-418.

Sowley, E.N.K. and Oduro, K.A. (2002) 'Effectiveness of curing in controlling fungal-induced storage rot in sweetpotato in Ghana', Journal of Tropical Science, 42, No. 1, pp.6-10.

Tomlins, K., Rees, D., Coote, C., Bechoff, A., Okwadi, J., Massingue, J., Ray, R. and Westby, A. (2010) 'Sweet potato utilization, storage, small-scale processing and marketing in Africa', in Ray, R.C. and Tomlins, K.I. (Eds.): Sweet Potato: Post Harvest Aspects in Food, Feed and Industry, Nova Science Publishers, Inc., New York, pp.271-293.

Tomlins, K.I., Ndunguru, G., Kimenya, F., Ngendello, T.E.R., Amour, R., Van Oirschot, Q. and Westby, A. (2007) 'On-farm evaluation of methods for storing fresh sweet potato roots in East Africa', Journal of Tropical Science, Vol. 47, No. 4, pp.197-210.

Tumwegamire, S., Mwanga, R.O.M., Andrade, M., Low, J.W., Ssemakula, G.N., Laurie, S., Chipungu, P.F., Ndirigue, J., Agili, S., Karanja, L., Chiona, M., Njoku, J.C., Mtunda, K., Ricardo, J., Adofo, K., Carey, E. and Gruneberg, W.J. (2014) Orange-Fleshed Sweetpotato for Africa. Catalogue 2014, 2nd ed., International Potato Center (CIP), Lima, Peru, p.74.

van Jaarsveld, J.P., Faber, M., Tanumihardjo, A.S., Nestel, P., Lombard, J.C. and Benadé, J.S.A. (2005) ' $\beta$-Carotene-rich orange-fleshed sweet potato improves the vitamin A status of primary school children assessed with the modified-relative-dose-response test', American Journal of Clinical Nutrition, Vol. 81, pp.1080-1087.

van Oirschot, Q., Ngendello, T., Rwiza, E., Amour, R., Tomlins, K., Rees, D. and Westby, A. (2007) 'The potential for storage of fresh sweetpotato under tropical conditions: evaluation of physiological changes and quality aspects', in Kapinga, R.E., Kingamkono, R., Msabaha, M., Ndunguru, J., Lemaga, B. and Tusiime, G. (Eds.): Tropical Root and Tuber Crops: Opportunities for Poverty Alleviation and Sustainable Livelihoods in Developing Countries: Proceedings of the Thirteenth Triennial Symposium of the International Society for Tropical Root Crops (ISTRC), Vol. 423-434, International Society for Tropical Root Crops, Arusha, Tanzania.

van Oirschot, Q.E.A., Rees, D., Lucas, C., Maina, D., Mcharo, T. and Bohac, J. (2001) 'Sweetpotato: germplasm evaluation for wound healing efficiency', Acta Horticulturae, Vol. 584, pp.31-40.

Walter Jr., W.M., Hammett, L.K. and Giesbrech, F.G. (1989) 'Wound healing and weight loss of sweet potato harvested at several soil temperatures', Journal of the American Society for Horticultural Science, Vol. 114, No. 1, pp.94-100.

Woolfe, J.A. (1992) Sweet Potato: An Untapped Food Resource, Cambridge University Press, Cambridge, UK. 